\title{
Taxi-out Time Prediction for Departures at Charlotte Airport Using Machine Learning Techniques
}

Hanbong Lee

\author{
$3^{\text {rd }}$ Joint Workshop \\ for KAIA/KARI - NASA ATM Research Collaboration \\ NASA Ames Research Center
}

October 24-26, 2016 


\section{Outline}

- Introduction: Aircraft taxi time prediction

- Charlotte Douglas International Airport (CLT)

- Taxi-out time data analysis

- Taxi time prediction using machine learning techniques

- Prediction performance evaluation

- Ongoing work for ATD-2

- Linear regression model with live data at CLT 


\section{Motivation}

- Taxi-out time for departing aircraft

- Ground movement time from pushback to takeoff

- Depend on taxi route and surface congestion

- Aircraft taxi time prediction

- Increase takeoff time predictability

- Improve efficiency in airport surface operations

- Help controllers find better takeoff sequences to maximize runway throughput

- However, accurate prediction is difficult.

- Uncertainties in airport operations

- Operational complexity 


\section{Previous Research}

- Queuing models for taxi-out time estimation

- Machine learning based approaches

- Linear regression models, Neural network model, Reinforcement learning algorithms, etc.

- Independently applied to limited data at several airports

- Taxi time prediction using machine learning methods and fast-time simulation (Lee, 2015)

- Used human-in-the-loop simulation data for CLT

- Possibly over-trained with limited datasets 


\section{Objectives}

- Analyze actual taxi time data at Charlotte airport (CLT)

- Identify unique operational characteristics of CLT

- Determine key factors affecting taxi times

- Develop precise taxi time prediction modules

- Based on taxi-out time data analysis

- Using machine learning techniques

- Evaluate taxi time prediction performance

- Using actual surface surveillance data at CLT

- Comparison of prediction methods

- Apply the taxi time prediction module to live data and incorporate it with a tactical scheduler for ATD-2 project 


\section{Charlotte International Airport (CLT)}

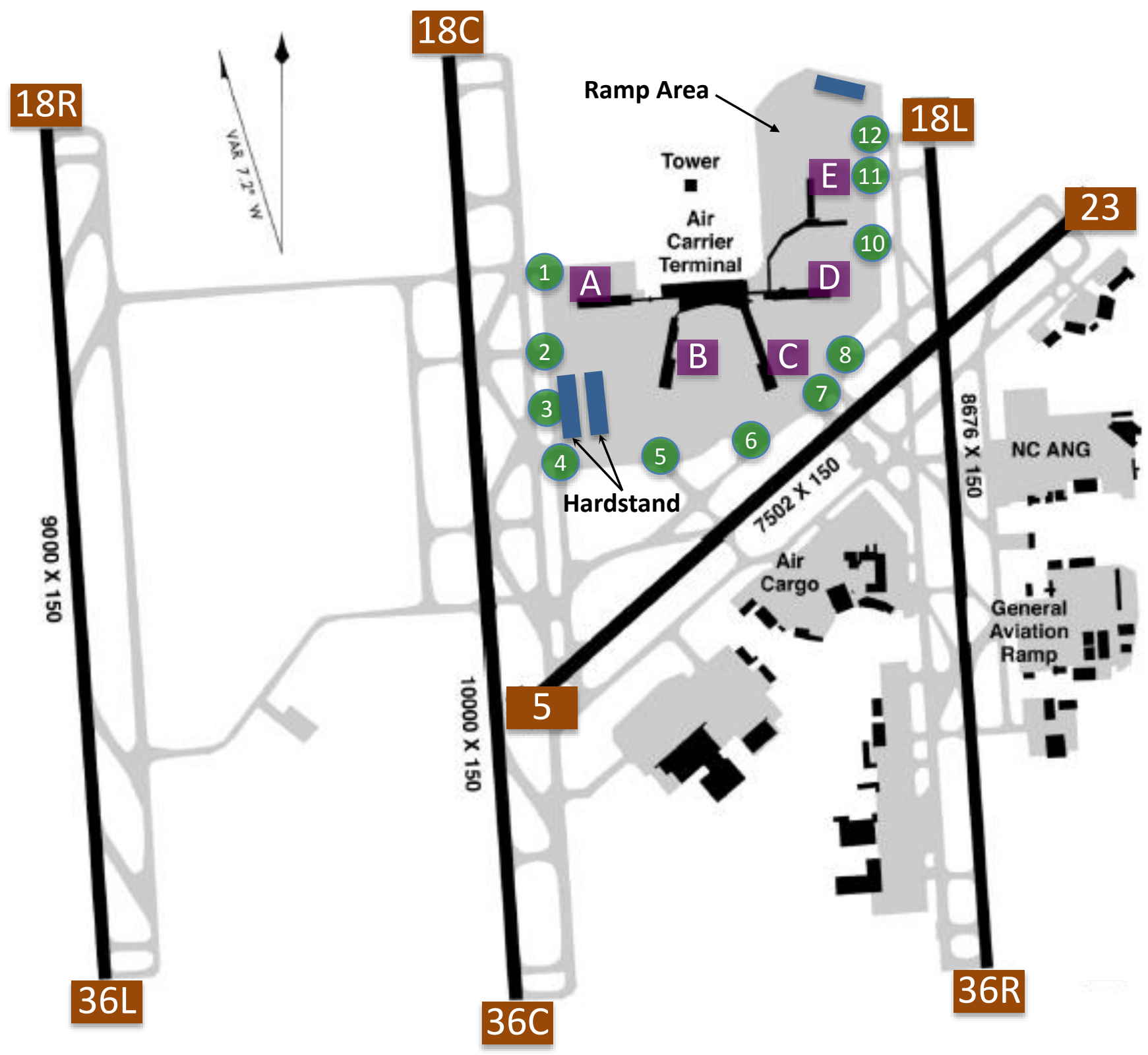




\section{Taxi-Out Time Data Analysis}

- Taxi-out time data

- Used actual flight data at CLT in 2014

- Analyzed 246,083 departures after data filtering

- Taxi-out times categorized by

- Terminal concourse

- Spot

- Runway

- Departure fix

- Aircraft weight class

- Month 


\section{Taxi Time by Terminal}

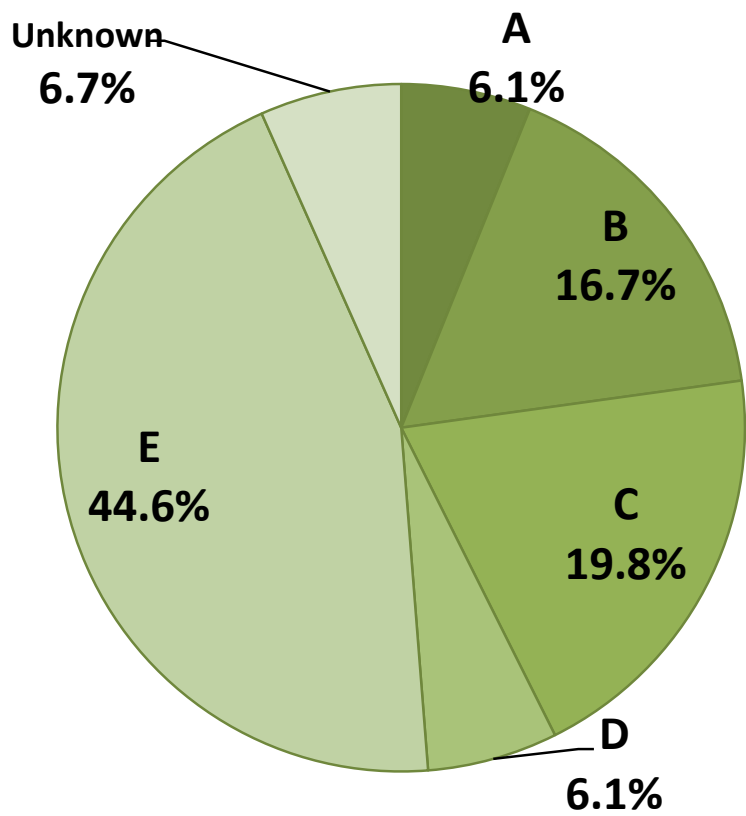

Departure distribution by terminal concourse

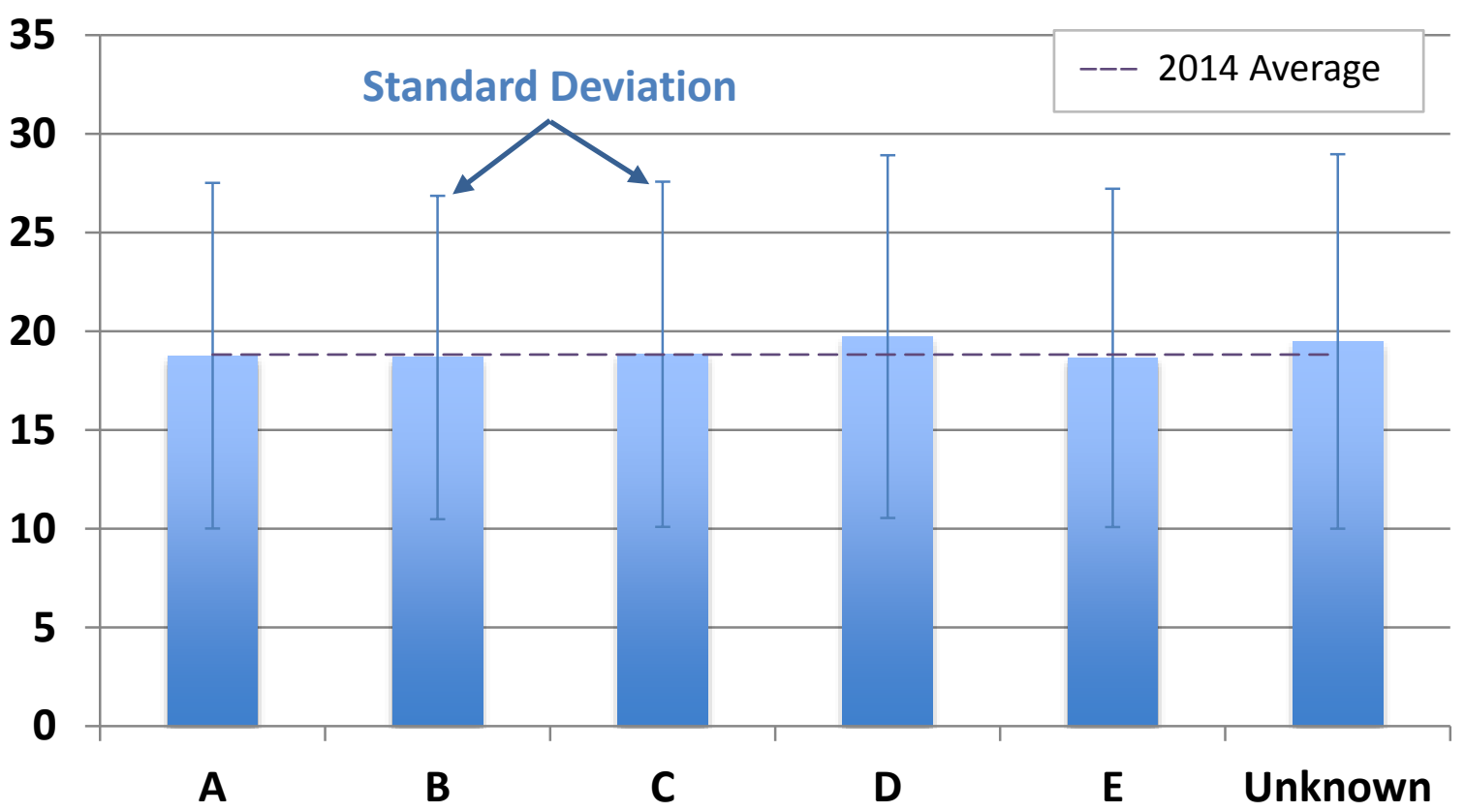

Average taxi-out time (in minutes) by terminal concourse

Average taxi time seems insensitive to terminal concourse, except for concourse $D$ used by international flights. 


\section{Taxi Time by Spot}

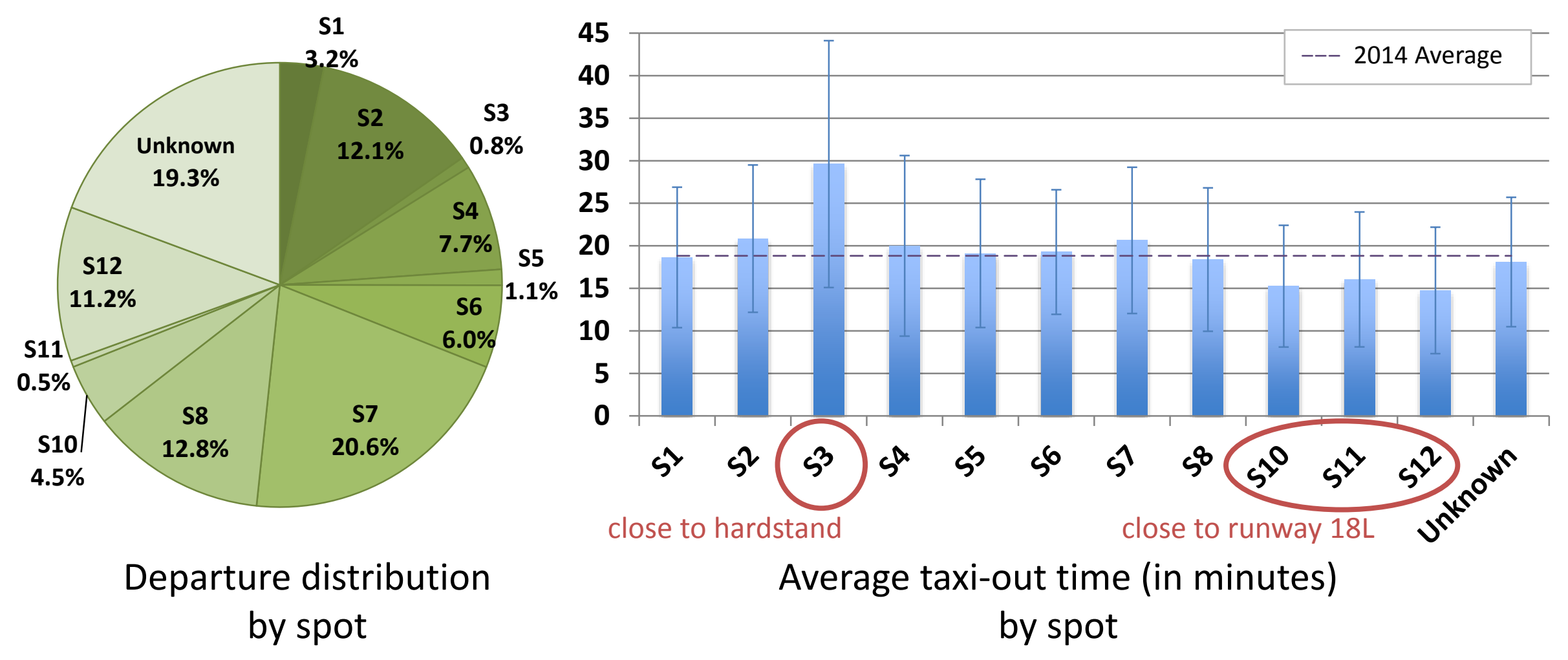

Spots S10, S11 and S12 are assigned to flights from concourse $\mathrm{D} / \mathrm{E}$ to runway $18 \mathrm{~L}$, leading to short taxi time. 


\section{Taxi Time by Runway}

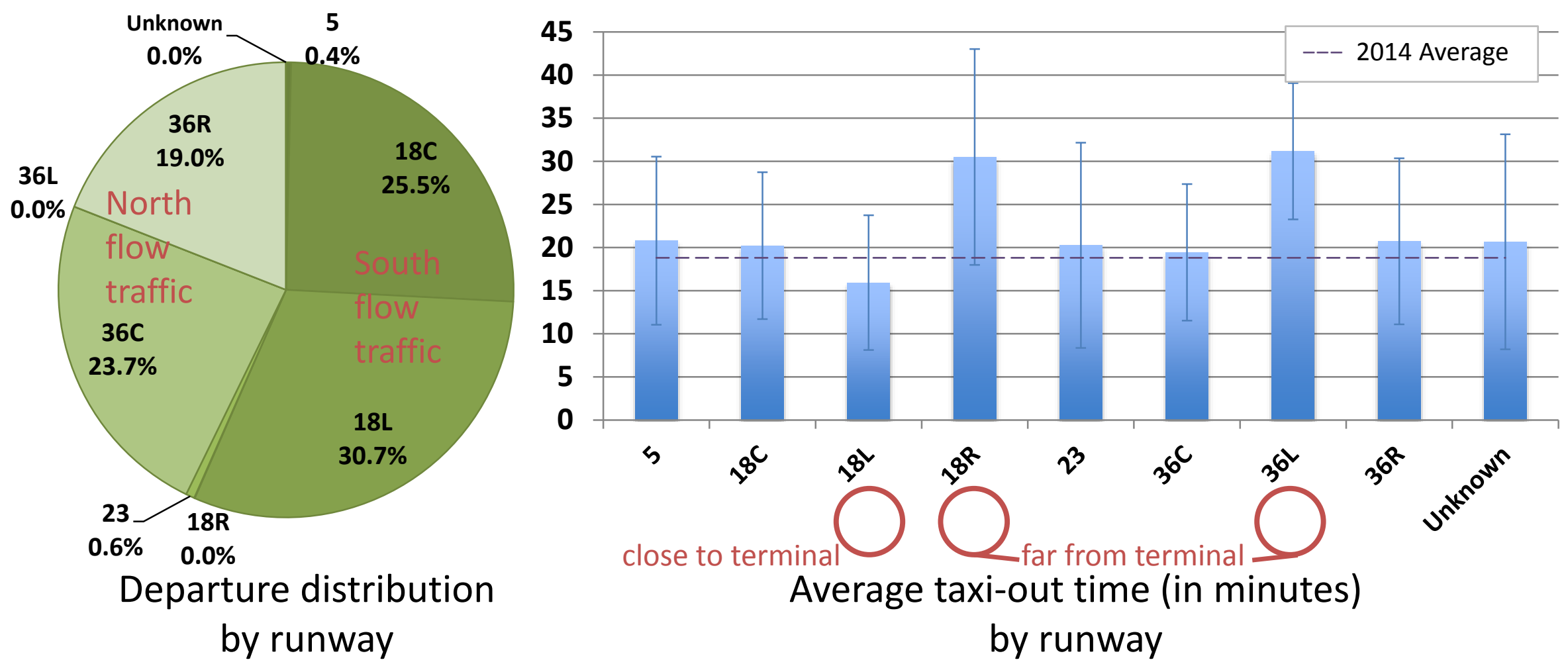

Taxi distance from terminal to runway affects taxi-out time directly. 


\section{Taxi Time by Departure Fix}

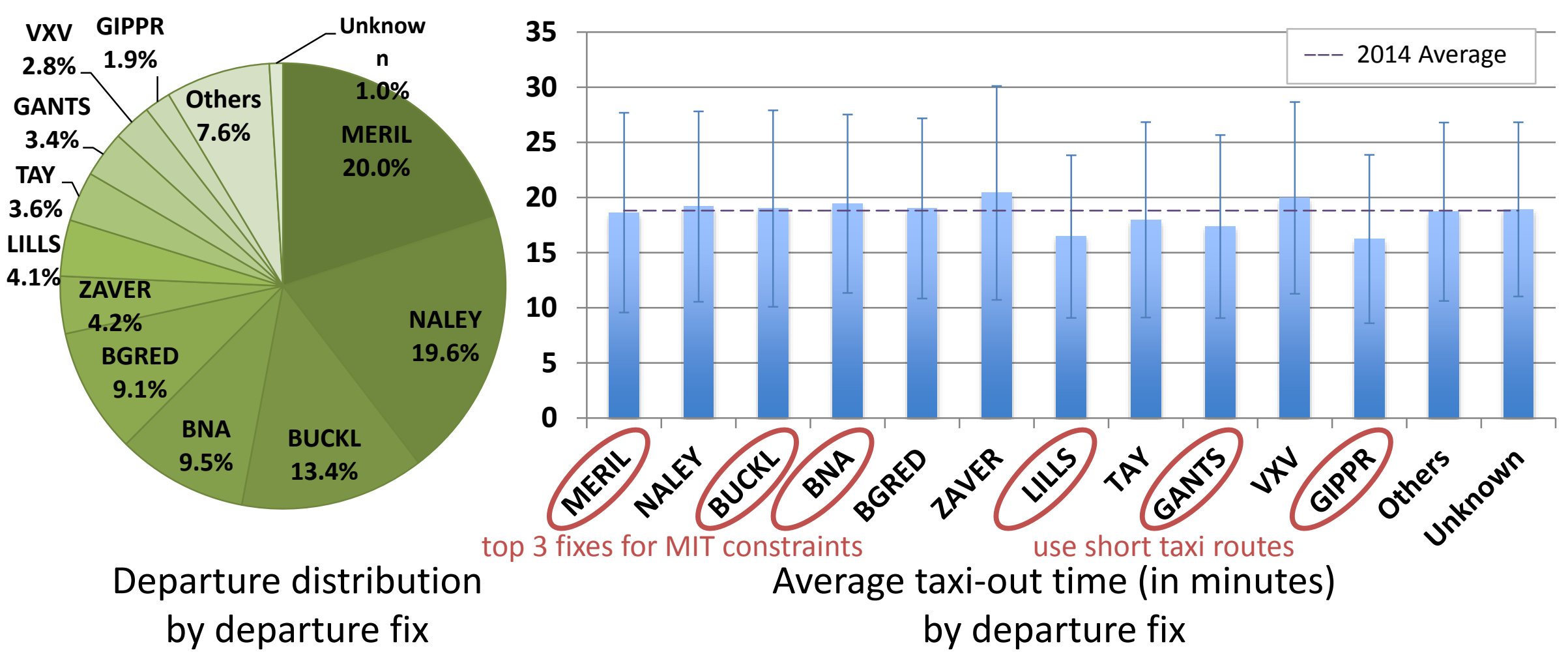

Taxi times of top 3 fixes for miles-in-trail (MIT) constrained departures are similar to the whole year average. 


\section{Taxi Time by Weight Class}

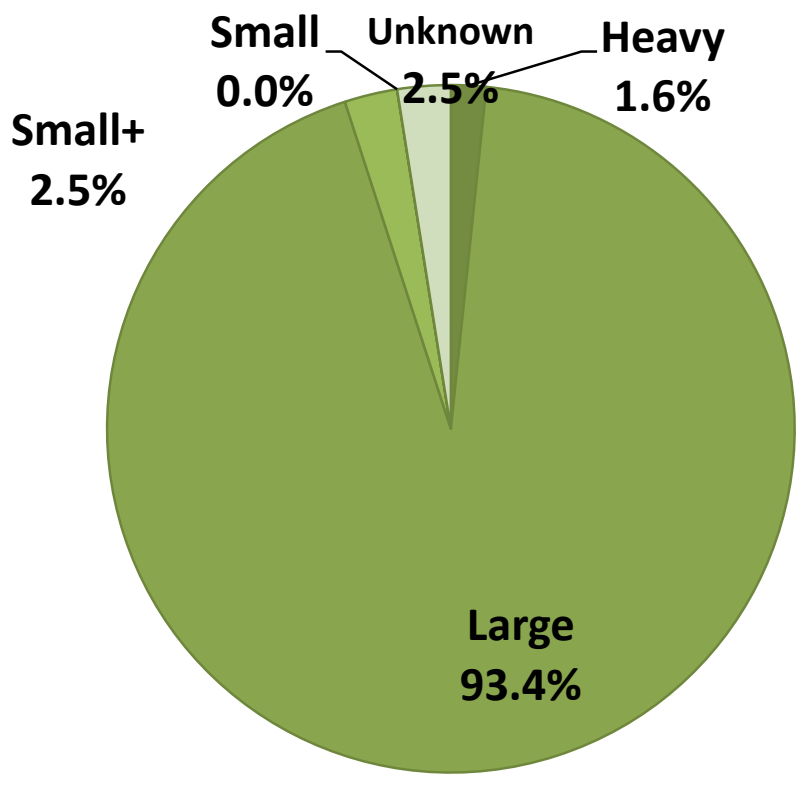

Departure distribution by weight class

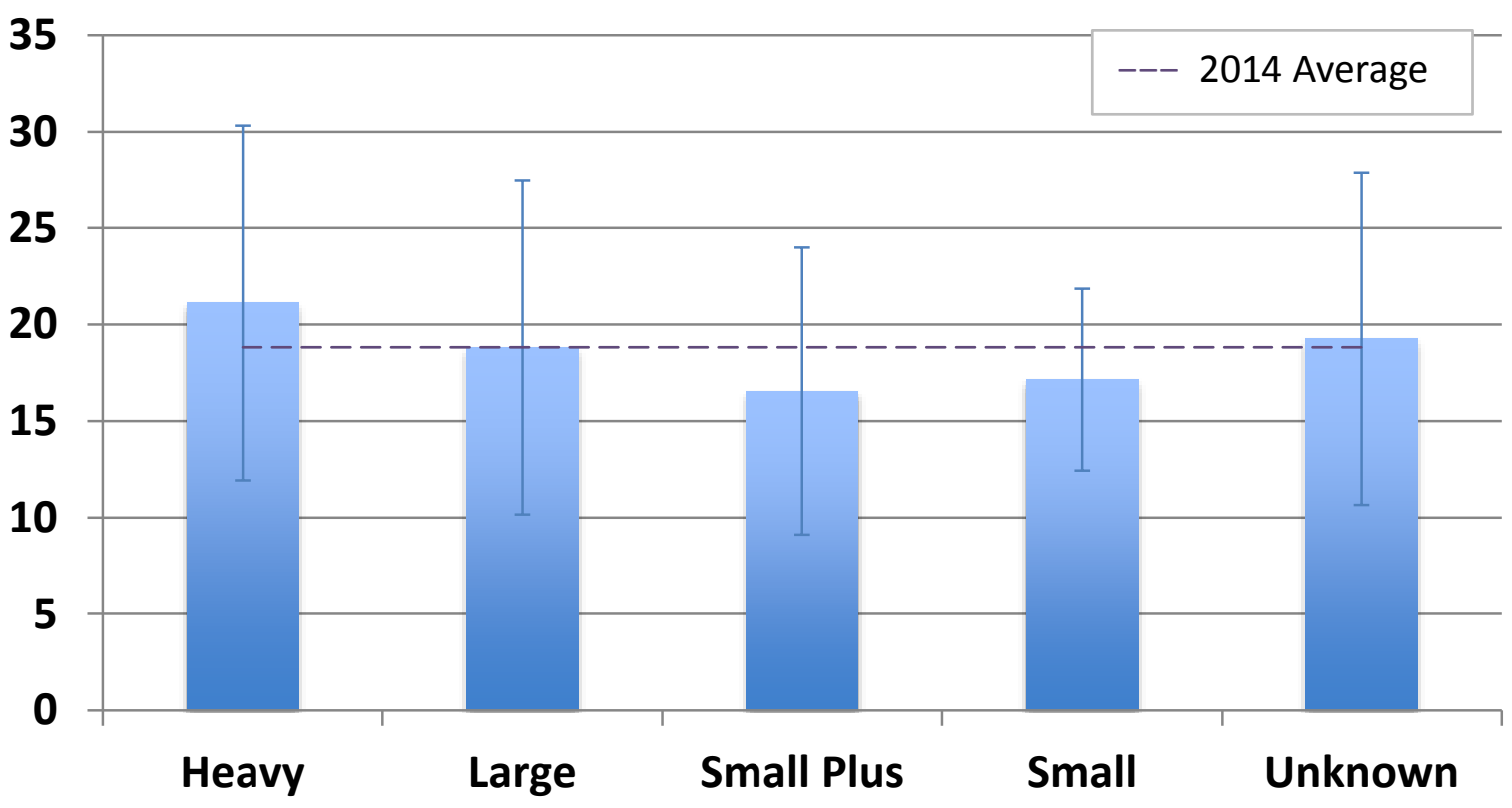

Average taxi-out time (in minutes)

by weight class

Heavy aircraft have relatively longer taxi times, whereas small aircraft have shorter taxi times. 


\section{Taxi Time by Month}

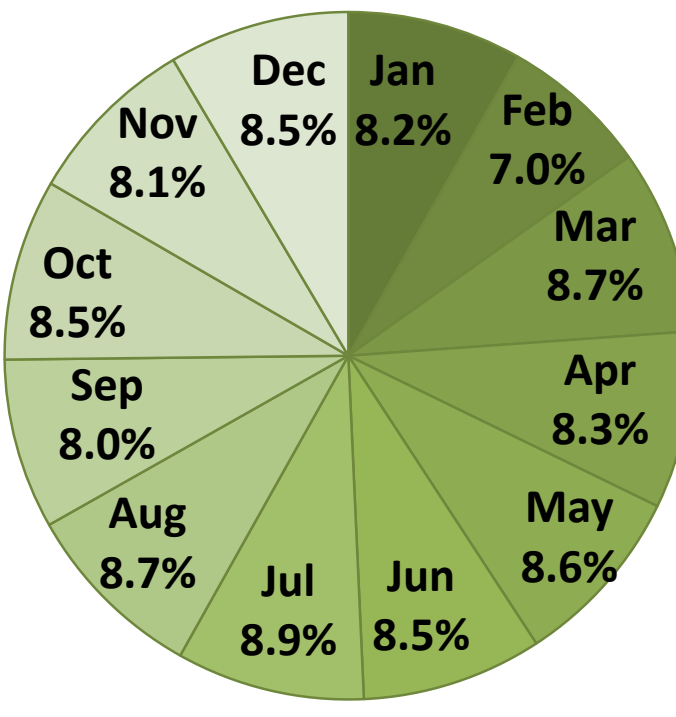

Departure distribution by month

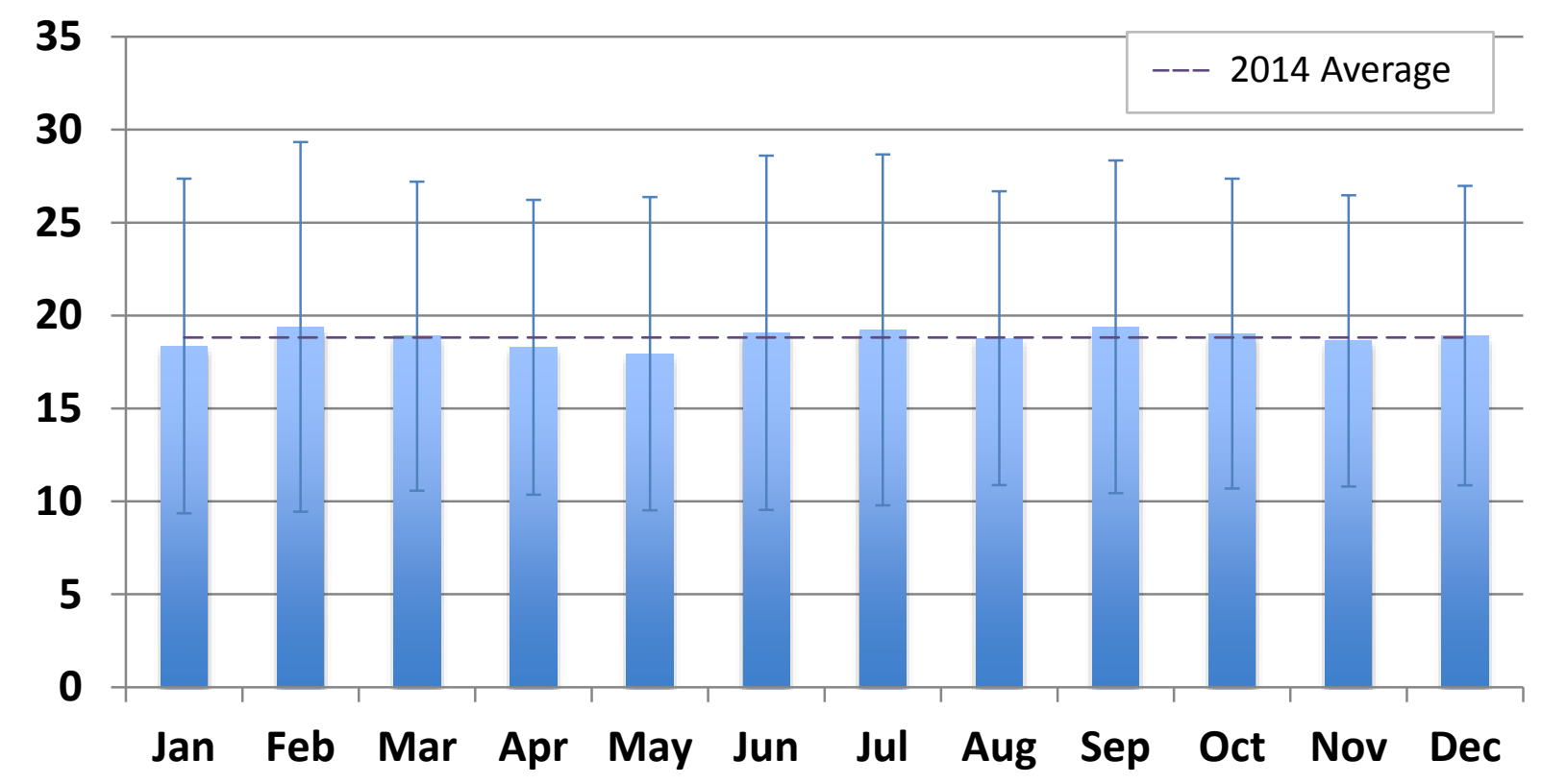

Average taxi-out time (in minutes) by month

Average taxi times are insensitive to month, meaning no seasonal effect on taxi-out time. 


\section{Taxi Time by Congestion Level}

- Separate data analysis using live data on 9/16-23/2016

- Average ramp taxi time as a function of congestion level in ramp area

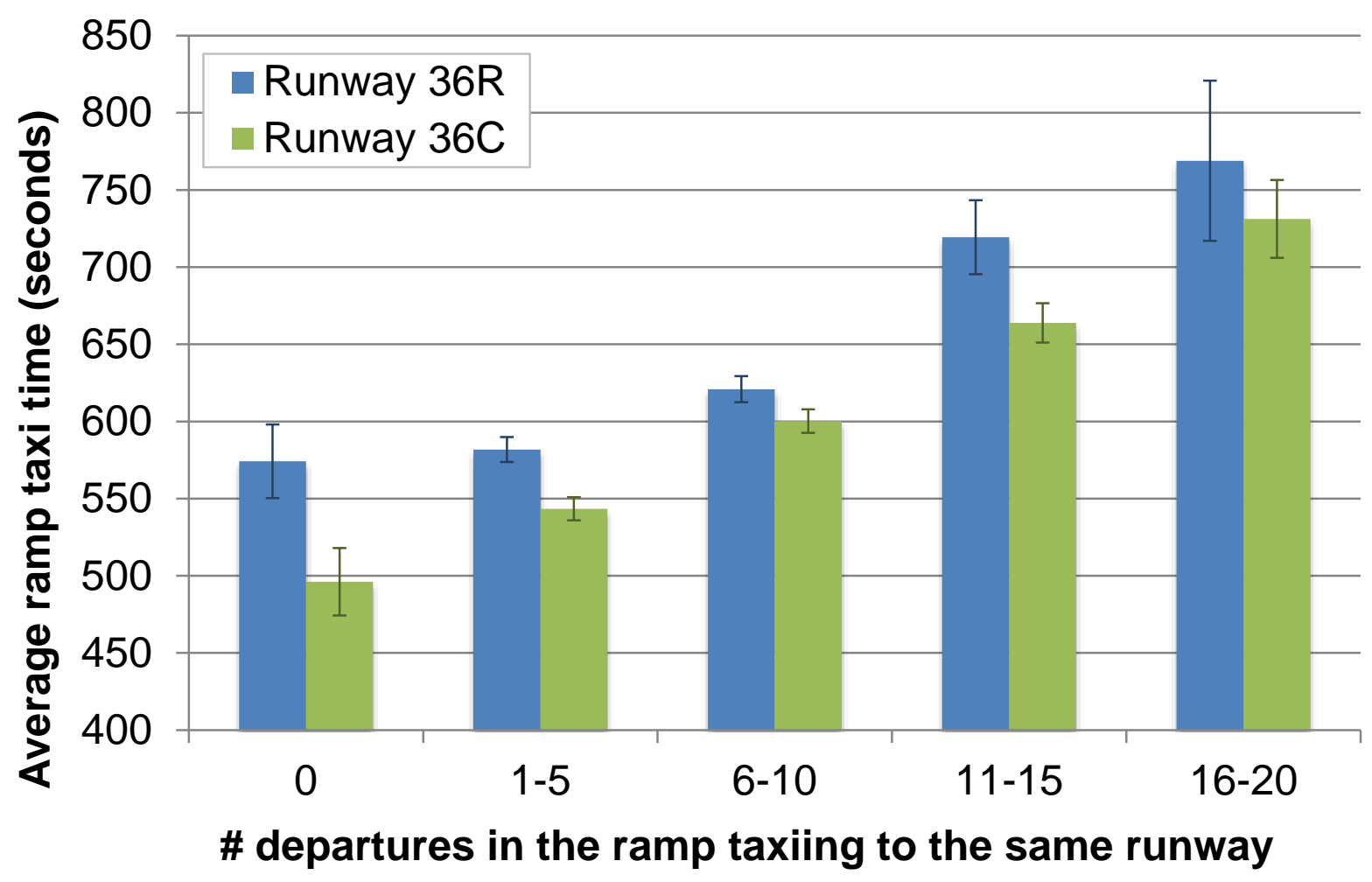




\section{Taxi Time Prediction Methods}

- Machine learning techniques tested

- Linear Regression (LR)

- Support Vector Machines (SVM)

- $k$-Nearest Neighbors (kNN)

- Random Forest (RF)

- Neural Networks (NN)

- Dead Reckoning (DR) method

- Baseline for comparison

- Based on unimpeded taxi times, defined as $10^{\text {th }}$ percentile of taxi times having the same gate, spot, and runway 


\section{Features}

- Terminal concourse and Gate

- Spot

- Runway

- Departure fix

- Weight class and Aircraft model

- Taxi distance

- Unimpeded taxi time

- Scheduled pushback time of day

- Number of departures and arrivals on the surface 


\section{Training and Test Datasets}

- Two runway configurations: south flow and north flow

- Two weather conditions: good weather and heavy rain

\begin{tabular}{|c|c|c|c|c|c|c|}
\hline $\begin{array}{l}\text { Traffic } \\
\text { flow }\end{array}$ & Weather & Dataset & Dates & Data size & $\begin{array}{l}\text { Avg. Taxi } \\
\text { time (min) }\end{array}$ & $\begin{array}{l}\text { Std. Dev. } \\
\text { (min) }\end{array}$ \\
\hline \multirow{4}{*}{$\begin{array}{l}\text { South } \\
\text { flow } \\
\text { traffic }\end{array}$} & \multirow[t]{2}{*}{$\begin{array}{l}\text { Good } \\
\text { weather }\end{array}$} & Training & $\begin{array}{l}6 / 1,6 / 2,6 / 4 \\
6 / 7,6 / 15\end{array}$ & 3,361 & 17.11 & 6.65 \\
\hline & & Test & $8 / 15$ & 689 & 17.78 & 6.59 \\
\hline & \multirow[t]{2}{*}{ Rain } & Training & $\begin{array}{l}6 / 11,6 / 12,6 / 25 \\
7 / 9,8 / 11\end{array}$ & 3,280 & 17.98 & 6.99 \\
\hline & & Test & $8 / 12$ & 644 & 17.68 & 6.51 \\
\hline \multirow{4}{*}{$\begin{array}{l}\text { North } \\
\text { flow } \\
\text { traffic }\end{array}$} & \multirow{2}{*}{$\begin{array}{l}\text { Good } \\
\text { weather }\end{array}$} & Training & $6 / 6,6 / 20,8 / 25$ & 2,134 & 19.32 & 6.13 \\
\hline & & Test & $8 / 26$ & 684 & 19.36 & 6.09 \\
\hline & \multirow[t]{2}{*}{ Rain } & Training & $7 / 21,8 / 1,8 / 23$ & 1,944 & 18.83 & 6.25 \\
\hline & & Test & $8 / 24$ & 621 & 19.31 & 6.32 \\
\hline
\end{tabular}




\section{Prediction Results - South Flow}

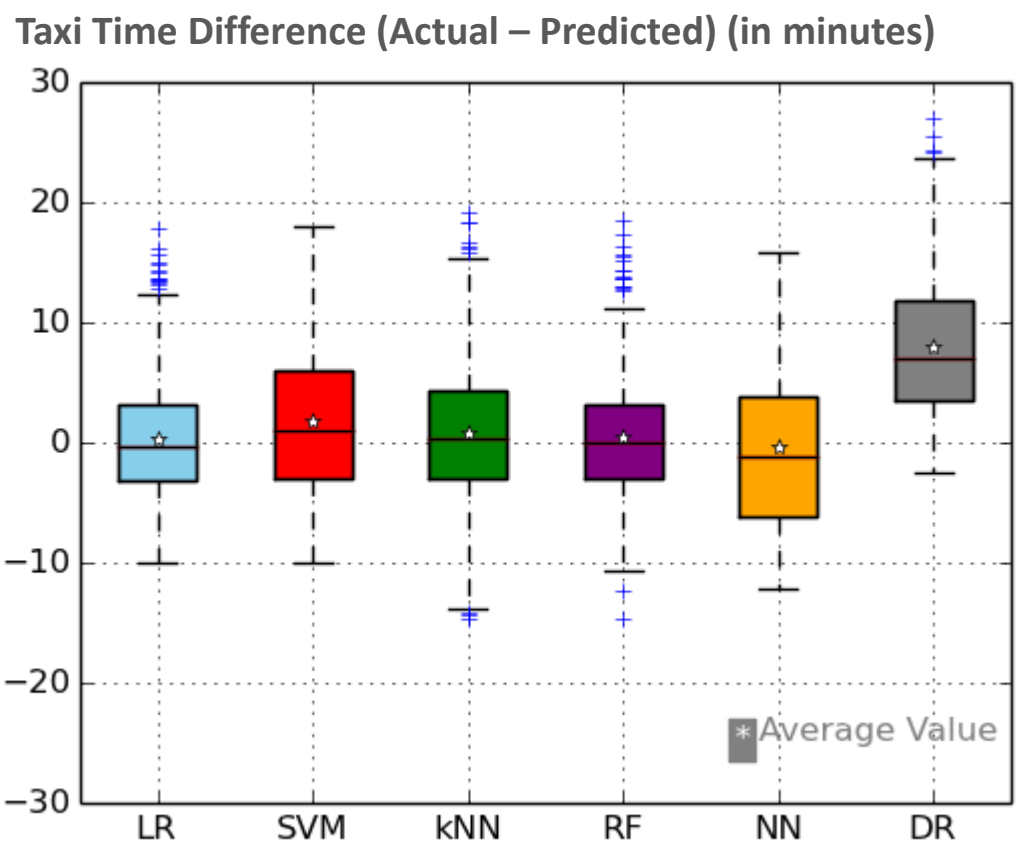

South-flow traffic, good weather

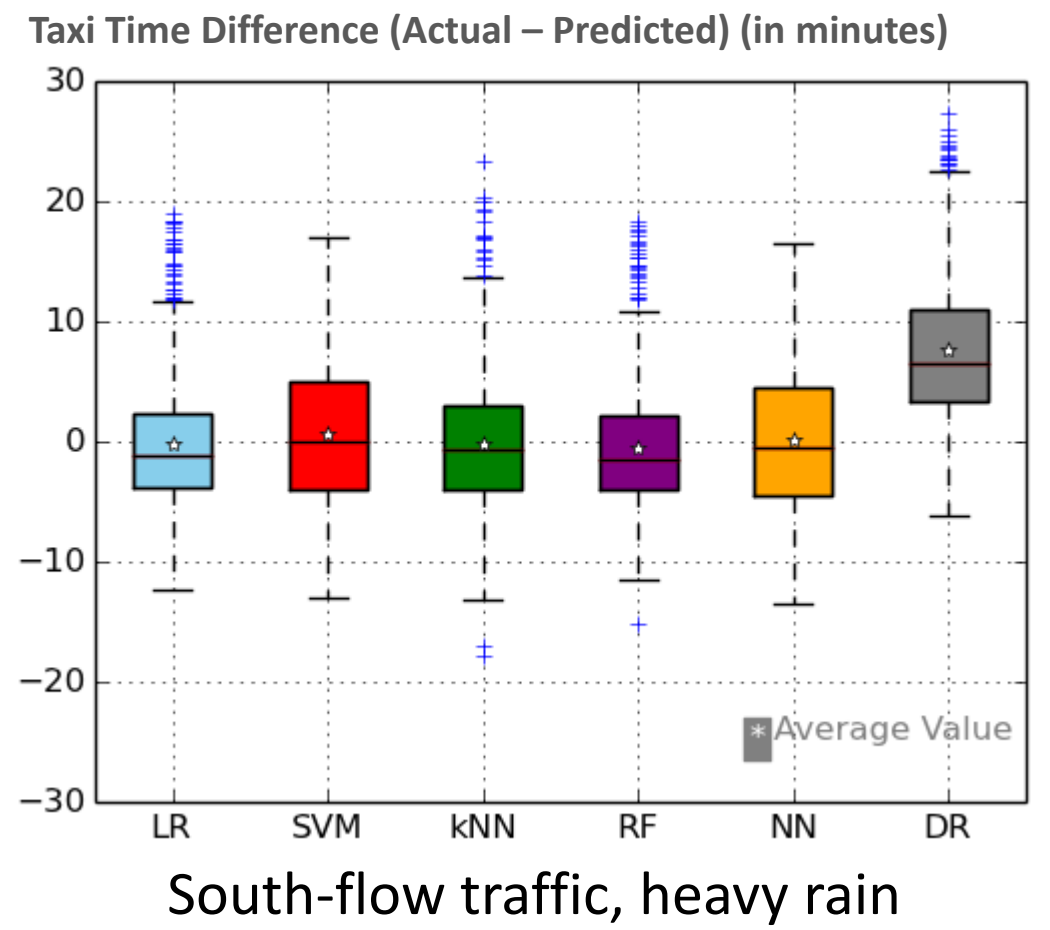

Machine learning algorithms show better performance than Dead Reckoning (DR) method. Linear Regression (LR) and Random Forest (RF) are the best. 


\section{Prediction Results - North Flow}
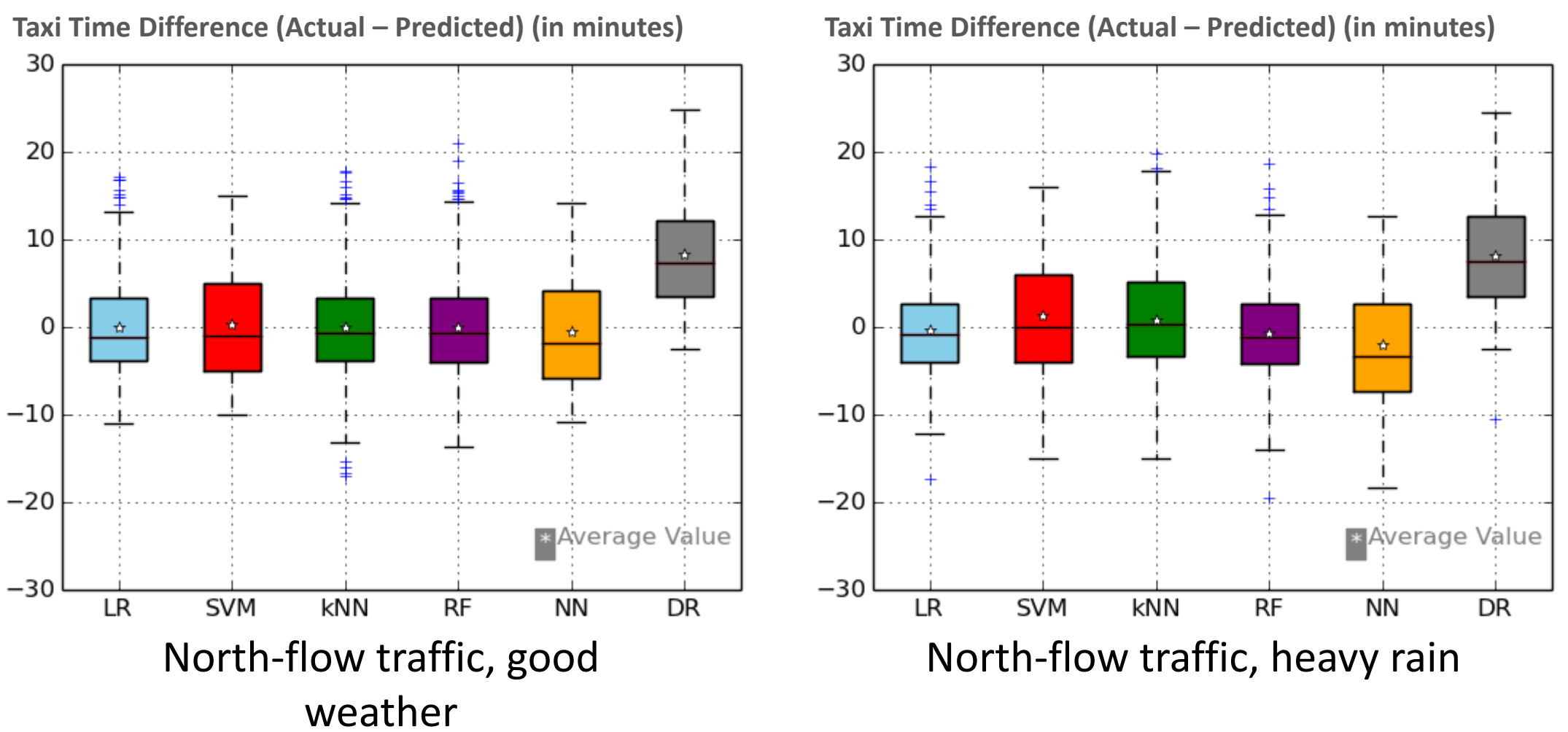

Linear Regression (LR) and Random Forest (RF) are still the best prediction methods for both traffic flow. 


\section{Conclusions}

- Analyzed the whole year taxi time data at CLT

- Found several factors affecting taxi-out time

- No seasonal effect on taxi time

- Applied various machine learning techniques to actual flight data at CLT for taxi-out time prediction

- Machine learning methods were better than Dead Reckoning method based on unimpeded taxi time.

- Linear Regression and Random Forest methods showed the best prediction performance.

- Considered various operational factors, but still needs to be improved. 


\section{Ongoing Work for ATD-2}

- Apply a linear regression model to live data

- Focus on ramp taxi time prediction

- Update taxi speed decision trees used in Tactical Scheduler

- Current taxi speed decision trees based on historical flight data and taxi route data

- Two decision trees for estimating taxi-out times of departures and taxi-in times of arrivals

- Taxi speed values both in AMA and Ramp in knots

- Branches by runway, spot, ramp area, and weight class

- Need to account for congestion on the surface

- Count the number of aircraft moving on the surface when a departure is ready to push back 


\section{Linear Regression Model}

- Formula

$$
y^{f}=\text { Const }+\operatorname{Coeff}_{i} \times x_{i}^{f}
$$

$-x^{f}$ : variables for flight $f$

- $y^{f}:$ predicted ramp taxi time of flight $f$

- Constant and Coefficients determined by training dataset

- Variables

- Ramp taxi distance (from gate to spot)

- Binary variables

- Ramp area, spot, runway, weight class, and EDCT

- Scheduled off-block time

- Congestion factors

- Number of departures in ramp area (by runway and ramp area)

- Number of arrivals in ramp area (by ramp area)

- Departures in the previous 15 minutes

- Number of flights going to the same runway, and their mean taxi time

- Number of flights going to the same fix, and their mean taxi time 


\section{Linear Regression Result}

- Live data from CLT

- North-flow traffic both in training dataset (9/16-22/2016) and test dataset (9/23/2016)

- Prediction accuracy

- Departures within \pm 5 -min error window: 714 (89.8\%)

- Departures within \pm 3 -min error window: 549 (69.1\%)

Actual Taxi Time Distribution

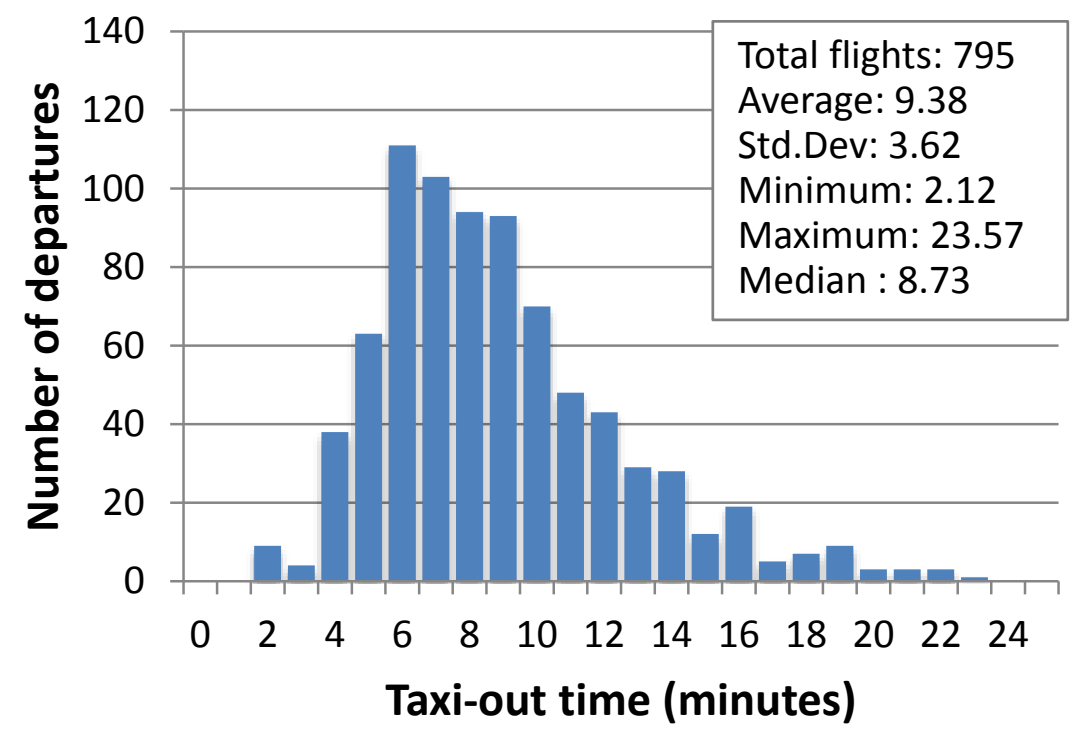

Taxi Time Difference Distribution

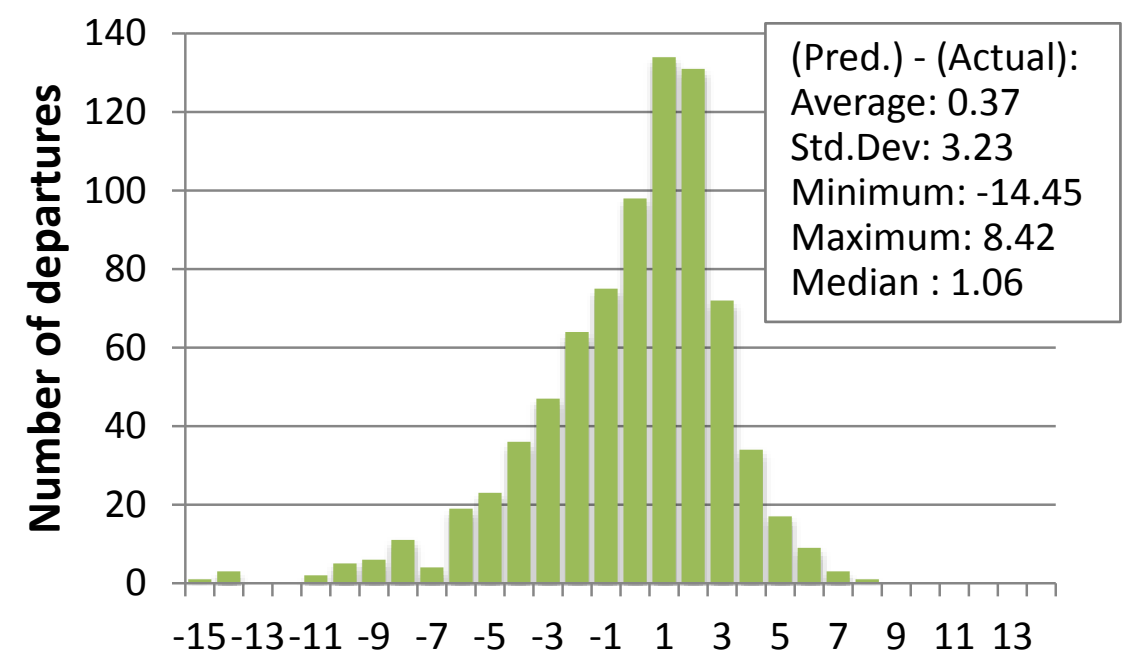

(Predicted) - (Actual taxi time) (minutes) $23 / 24$ 


\section{Linear Regression Example}

- AAL1832 from CLT to SAT (A319)

- Taxi route: $\mathrm{B} 8 \rightarrow \mathrm{S} 13 \rightarrow 36 \mathrm{C}$

- Default ramp distance from gate to spot: $370.5 \mathrm{~m}$

- Number of departures taxiing on surface: 6

- Two aircraft from each Concourse B, C, and E to runway 36C

- Linear Regression model

\begin{tabular}{|c|c|c|c|c|c|c|c|c|}
\hline Variable & $\begin{array}{l}\text { Ramp } \\
\text { Distance }\end{array}$ & B_EAST & Spot 13 & $\begin{array}{l}\text { Runway } \\
36 C\end{array}$ & $\begin{array}{l}\text { Weight } \\
\text { Class D }\end{array}$ & $\begin{array}{l}\text { Dep\# B } \\
\text { to } 36 C\end{array}$ & $\begin{array}{l}\text { Dep\# } \\
\text { C to } \\
36 C\end{array}$ & $\begin{array}{l}\text { Dep\# E } \\
\text { to } 36 \mathrm{C}\end{array}$ \\
\hline $\begin{array}{l}\text { Coefficien } \\
t\end{array}$ & 0.2735 & 166.2 & 28.6 & 189.6 & 74.2 & 9.9 & -1.3 & 4.6 \\
\hline
\end{tabular}

- Actual ramp taxi time: 573 seconds (Difference: 13.3 seconds)

- Predicted taxi speed in ramp area: $370.5 /(586.3-260)=2.2$ knots 